\title{
Endoscopic features of short-term progression of esophageal intramural pseudodiverticulosis
}

A 58-year-old man presented with an 8year history of intermittent dysphagia. There was no other relevant medical history. A barium esophagogram revealed a stenotic lesion in the middle and lower thoracic esophagus with multiple intramural tracks [1]. Endoscopic examination revealed an annular stricture of the esophagus extending from $27 \mathrm{~cm}$ to $40 \mathrm{~cm}$ from the incisors, as well as multiple small orifices ( $\bullet$ Fig. 1).

A diagnosis of esophageal intramural pseudodiverticulosis (EIPD) was suspected. As the patient did not have diabetes, candidal esophagitis, or esophageal carcinoma, and because esophageal inflammation has been reported in up to $90 \%$ of patients with EIPD [2], we prescribed a proton-pump inhibitor to suppress gastric acid secretion. However, after 7 months, the patient could barely swallow food, and repeat endoscopy showed that the lesions had clearly progressed. The multiple diverticula had enlarged and the lumen was criss-crossed by multiple mucosal bridges ( $\bullet$ Fig. 2 ).

Computed tomography of the chest showed marked thickening of the esophageal wall with intramural air sacs running parallel to the lumen of the upper to lower thoracic esophagus ( $\mathbf{F i g}$. 3).

A subtotal esophagectomy was carried out in view of the recent worsening of symptoms and endoscopic findings. On histological examination, the esophageal wall was remarkably thickened by submucosal fibrosis and hypertrophic muscularis propria. Dilated excretory ducts were seen extending from the mucosal epithelium to the submucosal layer ( $\bullet$ Fig. 4).

There were no features of malignancy in the esophageal wall or the regional lymph nodes, and a final diagnosis of EIPD was made. After surgery, the patient's dysphagia improved, and he has remained asymptomatic on follow up.

To our knowledge, this is the first report of EIPD with a hypertrophic muscular layer in the esophageal wall, as demonstrated in a full-thickness histological specimen $[3,4]$. Furthermore, with serial endoscopy, we observed the progression of EIPD in the short term.

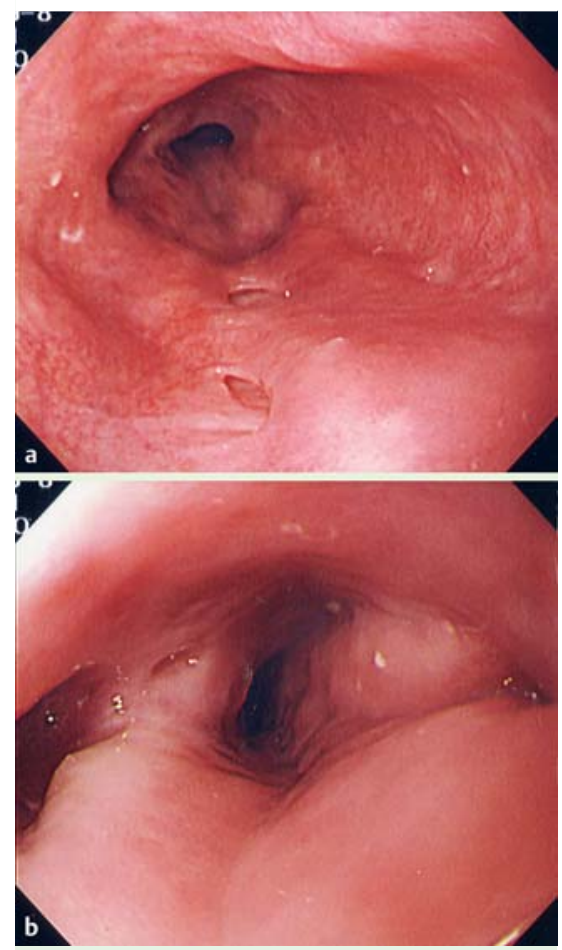

Fig. 1 Endoscopy showing: a multiple orifices in edematous mucosa in the middle thoracic esophagus; and $\mathbf{b}$ annular stenosis in the lower thoracic esophagus.

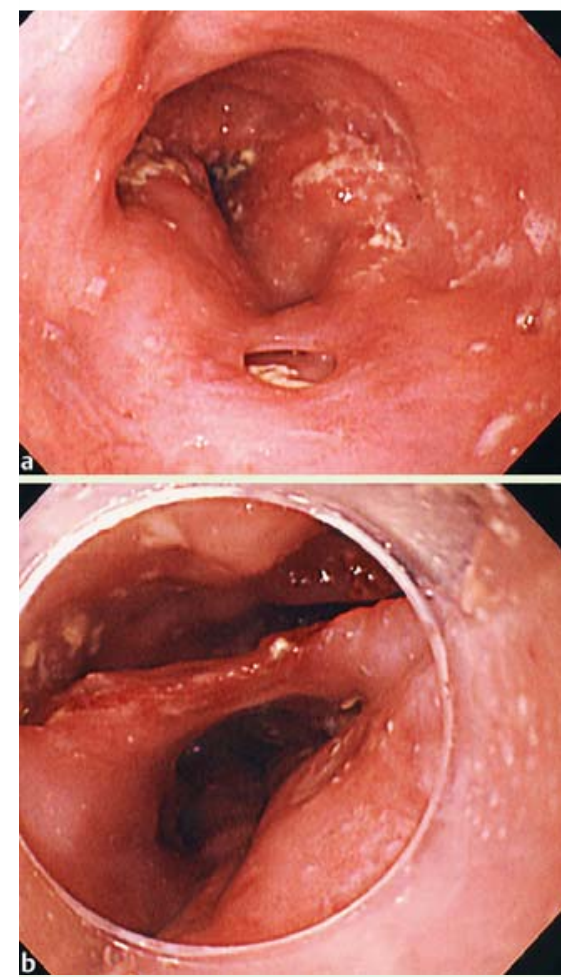

Fig. 2 Endoscopy showing: a the enlarged orifices; and $\mathbf{b}$ a thick mucosal bridge in the lower thoracic esophagus.

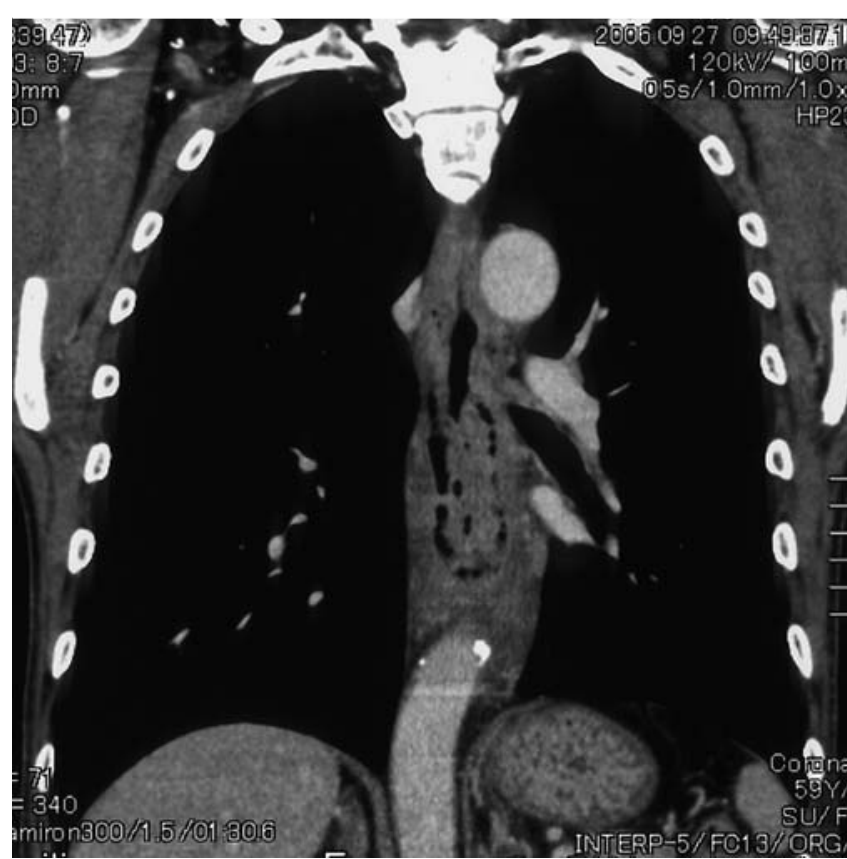

Fig. 3 Computed tomography (CT) scan showing a markedly thickened esophageal wall. Also seen are intramural air sacs, parallel to the lumen of the middle thoracic esophagus. 


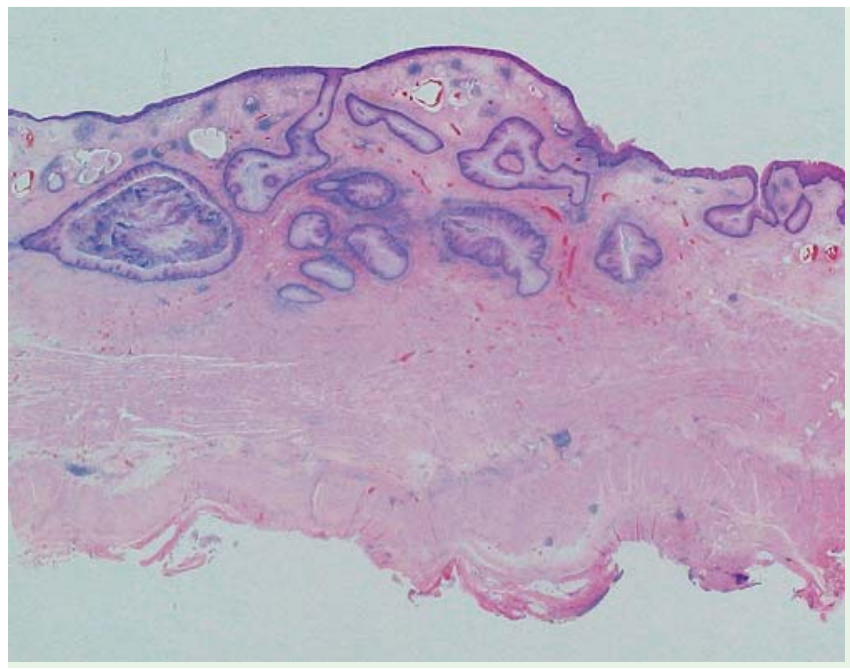

Fig. 4 Photomicrograph of the resected surgical specimen (hematoxylin and eosin, magnification $\times 40$ ). The esophageal wall is markedly thickened by submucosal fibrosis and the hypertrophic muscularis propria. Dilated excretory ducts extend from the mucosal epithelium to the submucosal layer. A keratin component, inflammatory cells, and fungal hyphae are seen in, and lymphocytes and plasma cells around, the ducts.

J. Tsuboi ${ }^{1,2}$, M. Tajika ${ }^{3}$, T. Nakamura ${ }^{3}$, H. Kawai ${ }^{3}$, V. Bhatia ${ }^{4}$, R. Takayama ${ }^{1}$, J. Kitamura ${ }^{5}$, Y. Yatabe ${ }^{5}$, S. Hatooka ${ }^{6}$, M. Shinoda ${ }^{6}$, K. Yamao ${ }^{1}$, Y. Ogura ${ }^{2}$

1 Department of Gastroenterology, Aichi Cancer Center Hospital, Nagoya, Japan

2 Department of Gastroenterology, Matsusaka City Hospital, Matsusaka, Japan

3 Department of Endoscopy, Aichi Cancer Center Hospital, Nagoya, Japan

\section{References}

1 Canon CL, Levine MS, Cherukuri R et al. Intramural tracking: a feature of esophageal intramural pseudodiverticulosis. Am J Roentgenol 2000; 175: $371-374$

2 Hahne M, Schilling D, Arnold JC et al. Esophageal intramural pseudodiverticulosis: review of symptom including upper gastrointestinal bleeding. J Clin Gastroenterol 2001; 33: $378-382$

3 Umlas J, Sakhuja R. The pathology of esophageal intramural pseudodiverticulosis. Am J Clin Pathol 1976; 65: 314-320

4 Kataoka H, Higa T, Koono M. An autopsy case of diffuse esophageal intramural pseudodiverticulitis. Acta Pathol Jpn 1992; 4 (Suppl 2): $837-840$

\section{Bibliography}

DOI $10.1055 / \mathrm{s}-0029-1243915$

Endoscopy 2010; 42: E92-E93

(c) Georg Thieme Verlag KG Stuttgart · New York . ISSN 0013-726X

\section{Corresponding author}

\section{Tajika, MD, PhD}

Department of Endoscopy

Aichi Cancer Center Hospital

1-1 Kanokoden

Chikusa-ku

Nagoya 464-8681

Japan

Fax: +81-52-7642942

mtajika@aichi-cc.jp 